\title{
Reflets
}

Revue ontaroise d'intervention sociale et communautaire

\section{L'Union culturelle des Franco-Ontariennes et la violence faite aux femmes et aux enfants}

\section{Nadya Dupuis}

Volume 2, numéro 1, printemps 1996

Contrer la violence subie par les femmes et les enfants en milieu

familial

URI : https://id.erudit.org/iderudit/026113ar

DOI : https://doi.org/10.7202/026113ar

Aller au sommaire du numéro

Éditeur(s)

Reflets : Revue ontaroise d'intervention sociale et communautaire

ISSN

1203-4576 (imprimé)

1712-8498 (numérique)

Découvrir la revue

Citer cet article

Dupuis, N. (1996). L'Union culturelle des Franco-Ontariennes et la violence faite aux femmes et aux enfants. Reflets, 2(1), 166-168.

https://doi.org/10.7202/026113ar

Tous droits réservés (C) Reflets : Revue ontaroise d'intervention sociale et communautaire, 1996
Ce document est protégé par la loi sur le droit d'auteur. L'utilisation des services d'Érudit (y compris la reproduction) est assujettie à sa politique d'utilisation que vous pouvez consulter en ligne.

https://apropos.erudit.org/fr/usagers/politique-dutilisation/ 


\section{L'Union culturelle des Franco- Ontariennes et la violence faite aux femmes et aux enfants}

\section{$N$ adya $D$ upuis}

A gente de développement, U nion aulturelle des F ranco- 0 ntariens (U C F O ).

Depuis sa fondation en 1936, I'U nion culturelle des FrancoO ntariennes (UCFO) s'est efforcée d'améliorer les conditions de vie des Franco-O ntariennes, et de promouvoir les droits des femmes et des francophones en général. A u fil des années, l'organisme a consacré beaucoup d'énergie à l'élaboration et à la mise sur pied de programmes visant à développer les ressources et les réseaux d'entraide communautaire. À l'aube de ses 60 ans, I'u c Fo porte une attention particulière au problème de la violence contre les femmes. L'organisation tient à informer, sensibiliser et conscientiser la communauté sur l'urgence de reconnaître que la violence faite aux femmes et aux enfants dans notre société est un problème collectif. En abordant ce problème, l'u cFo espère atteindre certains objectifs précis, en amenant la collectivité à :

- prendre conscience de l'ampleur de la violence faite aux femmes;

- voir la violence comme un acte criminel;

- reconnaître chez lesvictimes, toutes les manifestations de violence (physique, psychologique, sexuelle ou économique);

- analyser les valeurs sociales qui tolèrent cette violence;

- demander, voire même exiger des ressources collectives.

Dans sa lutte contre la violence, l'u cFo aborde des sujets aussi variés que les agressions sexuelles chez les adolescents, le dévoilement des agressions sexuelles, la violence conjugale dans 
le $\mathrm{N}$ ord de l'O ntario, la femme âgée et la violence familiale, et le rôle de la communauté face à la violence. Pour y parvenir, l'u c fo marraine la FESFo pour la publication de son bulletin d'information et de sensibilisation à la violence faite aux femmes Sans dé tour. Elle a également mis sur pied la pièce de théâtre Interdits, qui traite de l'agression sexuelle et de l'inceste. C ette pièce de théâtre donne la parole aux jeunes et encourage des rapports harmonieux entre hommes, femmes et enfants.

En 1992, l'u cFo a lancé $L$ a lumière des mots, bande vidéo de 40 minutes, montrant l'importance pour les femmes de dévoiler toutes les formes d'agression sexuelle. L a lumière des mots offre les témoignages de femmes franco-ontariennes qui confirment que l'agression sexuelle est un problème social, ayant des conséquences graves pour les personnes qui l'ont vécu. C'est un outil de prise de conscience et de cheminement pour la personne vivant ou ayant vécu une agression sexuelle, ainsi qu'un outil d'information et de formation pour toute personne qui s'intéresse à cette problématique.

L'U CFO a également fait partie du comité organisateur du premier colloque provincial sur les agressions sexuelles, Sensibiliser, décider et agir. C e colloque avait comme principal objectif de permettre aux femmes d'expression française de se rallier et de se concerter afin d'agir collectivement contre les agressions sexuelles dans le milieu ontarien. Finalement, afin de parler de la réalité des agressions sexuelles et de la rendre plus accessible, l'u c fo a produit et distribue, à l'échelle de la province, le dépliant sur les agressions sexuelles $Q$ ue faire? S' informer, réagir, s' entraider. Tout en offrant destémoignages, ce dépliant dresse une liste des ressources locales et provinciales.

Finalement, qu'il s'agisse d'inceste, de viol, d'agression à caractère sexuel, de violence physique ou psychologique, ou de harcèlement, tous ces comportements abusifs sinscrivent dans un rapport de force et de domination que les hommes exercent sur les femmes. A fin de le contrer, I'u c Fo travaille à conscientiser la société, à ne plus passer sous silence ces problèmes et leurs conséquences sur les femmes et les enfants. La bibliographie qui suit témoigne de cette lutte. $C$ es quelques ouvrages de référence 
sur les agressionsà caractère sexuel et la violence contre les femmes et les enfants sont disponibles au siège social de l'u cFo.

\section{Liste de documents de l'UCFO}

- Q ue faire? S'informer, réagir, s' entraider. D épliant sur les agressions sexuelles.

- Interdits: Prévention et sensibilisation aux abus sexuels et à l'inceste. Pièce de théâtre à l'intention des adolescentes et adolescents.

- L a lumière des mots.V idéo cassette traitant de l'effet du dévoilement des agressions sexuelles.

- M arc et Julie. Pièce de théâtre, tournée sur vidéo traitant de la violence conjugale. 